\title{
PASSION FOR INDIVIDUALITY AND SELF-IDENTITY IN THE POETRY OF MAMTA KALIA
}

\author{
Dr. Arvind Kumar
}

Associate Professor, Dept. of English

Shri K. K. Jain (P-G) College, Khatauli (U.P.)

\begin{abstract}
:
Indian writers in English, during pre and with their passion for Individuality and Self-Identity. The present paper aims show post-independence periods, have ever been extremely rich in their unique ways of presenting human emotions. Literature this Passion and Endeavour in the poetry of Mamta Kalia, a very prominent PostIndependence Indo-Anglian woman poet.
\end{abstract} being the best medium to express emotions and advocate ideas has a unique power of transcending all barriers of time and space. The manner in which it treats a particular theme and invests it with a universal meaning, binds the strangest of the people and remotest of the places. It delineates the inner-life and subtle impersonal relationships of the characters in a subtle and sensible way. The modern Indian women poets boldly shared their vision and mission and their emotions and aspirations through their writings. They have succeeded in establishing their identity in world literature and are firm to retain their identity at home too. Their characters too are setting new trends in the society. These poets dealt with new trends and themes in their poetry like Love, Sex, Man-Woman relationship, Betrayal, Loneliness and Identity crisis, etc. They used poetry as a powerful medium to bring about a social change. Kamala Das, Mamta Kalia, Imtiaz Dharker, Eunice D'Souza, Monika Verma and others, for instance, despite being Indian women from a traditional background, broke away the social barriers to elevate confessional poetry to the highest level and make it truly modern

Keywords: Post-Independence, Unique ways, Craftsmanship, Trends and Themes, Luminaries, Identity and Vision and Mission.

Literature is the best medium to express emotions and advocate ideas as it has a unique power of transcending all barriers of time and space. The manner in which it treats a particular theme and invests it with a universal meaning, binds the strangest of the people and remotest of the places. It delineates the inner-life and subtle impersonal relationships of the characters in a subtle and sensible way. It records dreams and desires, fears and furies, fact and fiction in its minutest details to soothe and soften mankind in hours of agony and anguish.

The Indo- Anglian women poets are motivating new generations with their revolutionary ideas today. They have a passion for individuality. Their 
characters are setting new trends in the society. Writers like Anita Desai, Shashi Deshpande, Manju Kapur, Shobha De, Kamla Das, Mamta Kalia, M. Silgardo, Eunice de Souza and Smita Agarwal are firmly advocating individuality in their writings. They vividly delineate the pains and sufferings of women in the country. They plead that sex exploitation and hypocrisy, traditional expectations of the family, obligations to society and snatching away of the individual freedom only results in identity crisis. They are not willing to tolerate any underhand dealings in the field of love and have no inhibitions in giving due place to sexuality and the demands of body.

Mamta Kalia is recognized as an important member of the new generation poets whose works are distinguished by the felicity, with which they have incorporated and adapted traditional forms of imaginative expression. Like Kamala Das, Mamta Kalia too has her distinct style and views, however, she finds herself divided into two worlds of tradition and modernity, freedom and bondage, domesticity and professionalism. The poetess has dared to speak out the minds and pronounce the anxieties, agonies and angers in high, brazen tones about her in reference to Indian women.

The post-independence era in India has been a phase of intense introspective search for roots and identity. Women, mainly those who had the opportunity to get education and facilities, also started to tear off their veils and assert their identity. In the same order, Mamta Kalia has also attempted to prove herself. Such attempts make clear her passion for individuality. Even in $21^{\text {st }}$ century most of the Indians carry ancient and traditional mentality. "There is no smoke without fire", keeping this famous proverb in mind, one must know the causes which increased her passion for individuality. For ease, the researcher puts them under some sub headings:

Her early life: Mrs. Mamta Kalia was born in Mathura. After schooling in Delhi, Nagpur, Bombay \& Pune, she earned a master's degree in English Literature from the University of Delhi in 1963. In her conversation with De Souza, Ms. Kalia informs us that her father was a teacher and a scholar of Hindi and English while her uncle, Bharat Bhushan Aggarwal, was a prominent poet of the progressive movement. her father wanted her to be different and superb. He compelled her to read certain inevitable writers such as Bankim, Sharat, Tagore, Nehru, Gandhi and Bertrand Russel while her own interest was in reading Donne, Blake, Eliot, Frost, Auden and Dylan Thomas along with other writers. But Ms. Kalia did not like it and this patriarch hovers over the title poem of her first volume, "Tribute to papa". She exclaims:

"You want me to be like you, Papa,

Or like Rani Lakshmibai, You're not sure what greatness is,

But you want me to be great."

Her passion for individuality is quite possibly motivated by an awareness of the pain that is 
encountered in the process of snapping filial bonds and challenging social taboos.Also, Her own near conventional lifestyle too supports this passion even though her poems may reflect a "rebellion against patriarchy" 1 William Walsh, 1990\} as William Walsh suggests, that leaves little or no room for choice.

Anybody can take a view of Mamta Kalia's personal agony by these lines. In this case, most of the Indian women will be agreeing with the poetess as they also suffer such critical situations in their day-to-day lives. They, too, want to prove themselves and show their identity but each of them is not Kalia or Kamala Das enriched with the skill of writing. Thus, it may also be a great cause to increase her passion for individuality and self-identity.

In the poem 'I Feel Like Crying All the Time', she cries out against the tedium of everyday household chores, which are coerced over woman by all the family members, and she also pronounces her boredom that she experiences in her love life:

"I feel like crying all the time

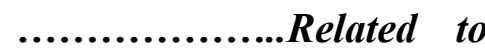

me."

Household responsibilities forced on her compel her to revolt against them. Another poem 'I am a Great Fool' presents the poetess's sense of ennui in her matrimonial relationship, where she finds marriage as hazardous to keep love alive. She cries in disillusionment:

\section{"I am a great fool}

To think that marriage is bliss,

Was it last month or last year

That we exchanged a kiss." Such cold relationship between husband and wife without mutual understanding and a heavy load of tasks cause a lot for her passions. In love and marital ties, Kalia finds living irony and paradox. Besides this, ego-clash makes difficult the moments what she and her husband need to share. She mentions of such quarrels in married life:

\section{"Every time I open my mouth, You feel let down, I try hard not to frown, If this goes on where will we end? \\ Or have we ended before we have begun?"}

- 'Dubious Lovers'

Mrs. Kalia is not at all happy with her marriage in a large family of the in-laws as she tells in her poem 'After Eight Years Of Marriage'. However, her suppressed emotions burst out:

"Instead, I cried, And in between sobs, nodded yes.

I wanted to tell them

And struggled hard from hurting myself.

That it wasn't easy to be happy in a family of twelve." 
Due to all these causes, the poetess has not been able to follow a full time writing career. One part obeying and performing its responsibilities and the other half raising its head well past midnight and scribbling away in diaries, on the back of envelops, on office file covers, working on an unfinished poem or story. This passionate concern for her poetic career is further compounded by her unease over the pain she experiences in the pursuance of a full time artistic vocation, on her fastidious husband, her two non-studious sons, her friends and old relatives.

Her poetry provides ample evidence of the effort that goes into striking a tenuous balance between relational expectations and responsibilities and individual proclivities. She admits herself that she likes to write at a time when her feelings are at her fingertips, but all her routine jobs take away the fire. Like most women writers, Kalia too is trapped in the dichotomy between her real lifestyle, her vocation and her gender. Having to juggle with several roles, she realizes that it is the creativity of the woman writer that is almost invariably relegated. Hence, her poetry shows a passion for individuality.

Other Causes: In other causes, the most compelling one is the oppression by fate. In our society, a woman cannot live her own life on her conditions. She is bound to many formalities and responsibilities. She is not free to do what she likes, to go where she wishes and to visualize her dreams. So many restrictions are forced on her. However, in many cases, these restrictions are for her safety because the society is corrupted with so many crimes. Yet she has a right to flourish her inner urge; but when she is crushed down under the wheels of fate, she cries out.

"Mamta Kalia is no strident, feminist activist either. Yet her poetry shares a vital concern with the basic proposition of women's demands for an equitable life" ${ }^{\text {"2 }}$ \{ Mina Surjit Singh, 2003\}

She has not only the passion for individuality and self-identity but also supports the feminist agenda for liberation from patriarchal oppression and other limitations. The early life, later life after marriage, and other causes which Mrs. Kalia faced, forced her to react in a different way. And the result comes forth in the form of her liberal views, her frustration and anger and her boldness on whispering topics:

i. Her Liberal Views: Mamta Kalia thematises her experiences of love, marriage, family and society in a simple, direct and conversational style and with poignant irony. In case of her father's idealistic attitude, she pours her liberal views in 'Tribute to Papa' :

“Who cares for you, papa?

Who cares for your clean thoughts, clean words, clean teeth......"

She has fairly liberal views but finds it hard to defy the commandments or sentiments of her tradition-bound father. As she states in the same poem at other place: 
"Everything about you clashes with nearly everything about me.

know you'll at once think of suicide.”

- 'Tribute to Papa'

Like Kamala Das and other women writers, Mamta Kalia is also very candid in her poetic expression. She shows a keen desire to jostle with the ground realities of human relationships.

As she reveals in her poem

'Compulsions':

"I want to pay Sunday visits

Totally undressed

I want to throw away

All my cosmetics

I want to reveal

My real age.”

Really these lines show Kalia's liberal views. Generally, a woman tries to dress properly and hide her real age, but the poetess has a great passion to prove her identity. Hence, she wishes to behave in a different way.

ii. Her Frustration: Her frustration bounds when she feels that her life has been a failure while she could do better to prove herself. In the poem 'Sheer Good Luck', she tells ironically and wittily how faded and luster-lack her wedded life has turned out to be :

\section{"So many things}

Could have happened to me....

But nothing ever happened to me

Except two children
And two miscarriages."

There are several other poems which convey woman's compromises and adjustments with her surroundings. Especially a working woman, who has also to perform her duties as a homemaker, finds it hard to come up with tedium of daily routine. She feels sandwiched between her place of work and household. On the one hand she has to bear the drudgery of her workplace, and on the other, she has to manage the sink full of plates, unwashed brushes, hosting meals, unmade beds and the similar irks at home. In the poem 'How like a Fool', she tells about her frustration, exhaustion and humiliation in the office:

"Here like a fool I've been working all along

When work is work's own defeat?

My promotion waits on your naughty knees

Readiness is all I now need"

“Mamta Kalia's descriptions bear the colour of realism and do speak of her felt experience. She finds poetry and apt medium to pronounce her grins and grudges". ${ }^{3}$ \{Kanwar Dinesh Singh, 2004\}

Most of her poems speak of her anger and dissatisfaction with life. Her aggression is mainly against the manmade and governed society wherein she fears of losing her individuality and selfidentify. In her poem 'Anonymous', she exclaims: 
"I no longer feel I'm Mamta Kalia,

I'm Kamala

Or Vimla, Or Kanta or Shanta.

I cook, I wash,

I bear, I rear,

I nag, I wag,

I sulk, I sag.....

and feel happy.

\section{I am no longer Mamta Kalia..."}

- 'Anonymous'

iii. Her Boldness: Kalia's passion for individuality and self-identity has similarity to Kamala Das. Although her married life did not prove a happier one, even then she misses her mate in her in free time. She very much desires the company of her husband whose long absence has made her almost lifeless. Sometimes she becomes sentimental while thinking of him. Nostalgically, she exclaims:

"Now I am away from you, Missing my hand cuffs/ feeling stupid

On this long unpromising sunday"

- 'Sunday Song'

Mamta Kalia's poetry in English is yet to receive the critical acclaim that it deserves. Her poetic strength evolves from her ability to maintain fine balance between her private and public life. She emerges as a quiet confident woman with a sound head on her responsible shoulders and her feet firmly planted on the ground. Without being openly defiant, she can hold on her own and is part of her society towards which she acknowledges a few explicit obligations and commitments. Her art is thus a symbiosis of the personal and the social along with her strong passion for individuality and self-identity.

References

William Walsh, Indian Literature In English (London and New York: Longman, 1990), p. 155.

Mina Surjit Singh, "Tradition and Skepticisn: Mamta Kalia" Six Women Poets: A Cross Cultural Study (New Delhi: Prestige Books, 2003), p. 174.

Kanwar Dinesh Singh, Feminism and Postfeminism: The Context of Modern Indian Women Poets Writing In English (New Delhi: Sarup and Sons, 2004), p. 88. 